\begin{tabular}{|c|c|c|}
\hline & Int.J.Curr.Microbiol.App.Sci (2021) 10(08): 429-434 & 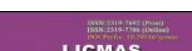 \\
\hline & $\begin{array}{l}\text { International Journal of Current Microbiology and Applied Sciences } \\
\text { ISSN: 2319-7706 Volume } 10 \text { Number } 08(\mathbf{2 0 2 1 )} \\
\text { Journal homepage: http://www.ijcmas.com }\end{array}$ & $\Rightarrow 98$ \\
\hline $\begin{array}{l}\text { EXCELLENT } \\
\text { PUBLISHERS }\end{array}$ & & wuwwijemas.com \\
\hline
\end{tabular}

Original Research Article

https://doi.org/10.20546/ijcmas.2021.1008.052

\title{
Seroprevalence of Viral Transfusion Transmitted Infections and Syphilis in a Tertiary Care Hospital from Haryana
}

\author{
Ashwini Manhas, Swati Mittal*, Vanita Mittal, Manju Meel, \\ Mehanaz Khan, Shashank Singh and K. C. Rathish \\ Department of Microbiology, Adesh Medical College, Kurukshetra, Haryana, India \\ *Corresponding author
}

Keywords

Transfusion

transmitted

infections,

Seroprevalence,

HIV, HCV, HBV,

Syphilis

Article Info

Accepted:

20 July 2021

Available Online:

10 August 2021

\section{A B S T R A C T}

Transfusion transmitted viral infections and syphilis pose a cross transmission risk to the uninfected patients and healthcare workers during the procedures or shared equipments. Most of the studies are conducted on either apparently healthy blood donors or specific patient groups with risk factors or comorbidities. This study was conducted to assess the overall seroprevalence amongst the patients visiting our hospital irrespective of the patient risk profile or comorbidities. This was a retrospective study utilizing the hospital records for a six month period from 10 October 2020 to 10 April 2021. Only non-duplicate patients and samples were considered for analysis. The study included 1123 individual patients. Of these 1123 patients, 649 were males whereas the remaining 474 were females. The observed seroprevalence of HIV was $0.91 \%$, HCV $2.22 \%$, HBV $1.3 \%$, and syphilis $1.66 \%$. The findings of the study are suggestive of a slightly higher seropositivity of HIV, HCV and HBV amongst the patients visiting this tertiary care centre when compared to the seroprevalence amongst healthy blood donors reported in the available studies from the region.

\section{Introduction}

Transfusion transmitted viral infections are a risk for both patients and healthcare workers in a tertiary care hospital treating patients with diverse comorbidities. These range from patients who are intravenous drug users, patients requiring hemodialysis due to chronic renal failure, patients requiring repeated blood transfusions, patients undergoing surgery and various other interventional procedures. ${ }^{1}$ All such patients are at a higher risk of being seropositive or undergoing seroconversion during or after treatment. The estimated prevalence of $\mathrm{HCV}$ in India is 0.5 to $1.5 \%,{ }^{2}$ for HBV a study found the pooled prevalence 
as $2.6 \%$ before 1989 , and $1.4 \%$ after $1989{ }^{3}$ whereas another modeling study found the seroprevalence of HBsAg in India in 2016 as $2.5 \%$ (95\% CI 2.2-2.7). ${ }^{4}$ According to national AIDS control organization (NACO) estimates, the prevalence of HIV in adults (15-49 years) in the year 2019 was $0.22 \% .^{5}$ The prevalence of syphilis in an STI clinic from north India was reported as $6.4 \%,{ }^{6}$ whereas another study from south India conducted on commercial sex workers observed the drop in high titre syphilis prevalence from $5.9 \%$ to $2.4 \%$ between the years 2004 and $2012 .{ }^{7}$ In a large syphilis seroprevalence study from north India the prevalence was observed to be $1.27 \% .^{8}$

The practice of routinely screening all the patients for Human immunodeficiency virus (HIV), Hepatitis C virus (HCV), and Hepatitis $B$ virus (HBV) at the time of hospital admission or before a surgery or interventional procedure is an important method of reducing the exposure risk amongst healthcare workers and cross transmission to other patients due to shared hospital equipment. Additionally, screening for syphilis by venereal disease research laboratory (VDRL) test or rapid plasma reagin (RPR) test is routinely performed in the antenatal clinic and STI clinic.

The prevalence of these infections should be periodically studied to assess the trends in community as the healthcare advancement and various interventions potentially increase the risk of hospital associated infections while at the same time an early diagnosis by routine screening may help curtail the transmission.

Most of the studies are performed either on healthy donors or on specific category of patients with a specific type of comorbidity. However, in a hospital these prevalence rates could vary if all the patient profiles are taken together into consideration. Therefore, this study was undertaken to assess the six month seroprevalence of $\mathrm{HIV}, \mathrm{HCV}, \mathrm{HBV}$, and syphilis in all the patients who underwent treatment and serological testing at Adesh Medical College and Hospital, Kurukshetra, Haryana.

\section{Materials and Methods}

The study was conducted at Adesh Medical College and Hospital, Kurukshetra, Haryana after due ethical approval by the institutional ethics and research committee (IERC).

The study period was six months, from 10 October 2020 to 10 April 2021. During this period any serological test performed for HIV, HCV, HBV, and syphilis on any patient who visited or was admitted to the hospital, was included in the study. This was a retrospective study which utilized the lab records to collect the details of the samples tested during this period. Only non-duplicate tests performed on the patients were included for further analysis.

The serological tests used for HIV serology (anti-HIV 1 \& 2 antibody) was an immunochromatographic method based rapid card test (HIV TRIDOT, J.MITRA). For HCV serological test (Anti-HCV antibody), an immunochromatographic method based rapid card test (HCV TRIDOT, J. MITRA) was used. For HBV serological test (HBsAg) an immunochromatographic method based rapid card test (HEPACARD, J. MITRA) was used. For the diagnosis of syphilis, anticardiolipin antibody RPR test (AGAPPE) was used.

\section{Results and Discussion}

The study included 1123 individual patients who were tested for one or more of the serological tests performed for transfusion transmitted infections which included HIV, HBV, HCV, and syphilis. Of these 1123 patients, 649 were males whereas the remaining 474 were females. Of 1123, 898 
patients were either admitted or reported to emergency ward whereas the remaining 225 reported to the outpatient departments. The highest numbers of requests were received from the emergency dept accounting for 417 patients $(37.1 \%)$. The distribution of age groups is shown below in Table 1. The most common age group was 18-35 years which included 376 patients followed by $36-50$ years which included 296 patients.

The HIV testing was performed in 1098 patients. Of these, 10 patients were seropositive for HIV accounting for an overall prevalence rate of $0.91 \%$. The age group distribution is shown in Table 2 below which showed a higher prevalence of $1.14 \%$ in $>65$ years old age group whereas this was lower in the age groups of $36-50$ years $(0.7 \%)$ and 51 65 years $(0.72 \%)$. No cases were detected in the age groups less than 18 years.

The HCV testing was performed in 1080 patients. Of these, 24 patients were seropositive for $\mathrm{HCV}$ accounting for an overall prevalence rate of $2.22 \%$. The age group distribution is shown in Table 3 below which showed a higher prevalence of $5.2 \%$ in 12-17 years age group followed by $3.29 \%$ in 51-65 years, and $2.52 \%$ in $36-50$ years. No cases were reported in less than 12 years age. Of these 24 reactive cases, 6 were from the dialysis unit thus contributing to about a quarter of the HCV seropositivity.

The HBV testing was performed in 1072 patients. Of these, 14 patients were seropositive for $\mathrm{HBV}$ accounting for an overall prevalence rate of $1.3 \%$. The age group distribution is shown in Table 4 below which showed a higher prevalence of $2.29 \%$ in $>65$ years age group, followed by $1.58 \%$ in
18-35 years and $1.09 \%$ in 51-65 years. No case were reported in $<18$ years of age. Testing for syphilis by RPR test was performed in 60 patients. Of these it was reported positive in 1 patient (reported titre $1: 16)$ accounting for an overall prevalence of $1.66 \%$ of the tested patients.

Transfusion transmitted viral infections (HIV, $\mathrm{HCV}$ and HBV), and syphilis carry a potential risk of cross transmission in the hospital due to shared equipments. Seropositive patients visit hospital due to various medical reasons and pose risk of accidental exposure to other patients or healthcare workers.

In our study it was observed that more than one third of requests for serological testing were received from the emergency department which is indicative of a good practice to assess the baseline status of the patient and enhancing caution amongst the healthcare staff while caring for a seropositive patient in the emergency.

The observed overall seropositivity rate of HIV was $0.91 \%$, HCV was $2.22 \%$ and HBV was $1.3 \%$ in our study. Comparing the age group distribution a proportionately higher HIV seropositivity was observed in $>65$ years age group, $1.14 \%$ for HIV and $2.29 \%$ for HBV. This is likely due to a significant contribution by hemodialysis patients which tested positive in our study. Hemodialysis is a known risk factor for higher seropositivity rates. ${ }^{9}$ The age predilection may be due to higher proportion of elderly population undergoing hemodialysis at our hospital due to chronic renal failure following various age related comorbid conditions such as diabetes or hypertension leading to chronic renal failure. 9 
Table.1 Distribution of age groups

\begin{tabular}{|c|c|}
\hline Age group & No. of patients tested \\
\hline $\mathbf{7 6 5}$ yrs & 176 \\
\hline $\mathbf{5 1 - 6 5}$ yrs & 278 \\
\hline $\mathbf{3 6 - 5 0}$ yrs & 289 \\
\hline $\mathbf{1 8 - 3 5}$ yrs & 347 \\
\hline $\mathbf{1 2 - 1 7}$ yrs & 19 \\
\hline $\mathbf{5 - 1 1}$ yrs & 11 \\
\hline $\mathbf{0 - 4}$ yrs & 3 \\
\hline Total & $\mathbf{1 1 2 3}$ \\
\hline
\end{tabular}

Table.2 Seroprevalence of HIV

\begin{tabular}{|c|c|c|c|}
\hline Age group & Nonreactive & Reactive (\%) & Total \\
\hline $\mathbf{7} \mathbf{6 5}$ yrs & 173 & $2(1.14 \%)$ & 175 \\
\hline $\mathbf{5 1 - 6 5}$ yrs & 274 & $2(0.72 \%)$ & 276 \\
\hline $\mathbf{3 6 - 5 0}$ yrs & 282 & $2(0.7 \%)$ & 284 \\
\hline $\mathbf{1 8 - 3 5}$ yrs & 327 & $4(1.2 \%)$ & 331 \\
\hline $\mathbf{1 2 - 1 7}$ yrs & 18 & NIL & 18 \\
\hline $\mathbf{5 - 1 1}$ yrs & 11 & NIL & 11 \\
\hline $\mathbf{0 - 4}$ yrs & 3 & NIL & 3 \\
\hline Total & $\mathbf{1 0 8 8}$ & $\mathbf{1 0}(\mathbf{0 . 9 1 \%})$ & $\mathbf{1 0 9 8}$ \\
\hline
\end{tabular}

Table.3 Seroprevalence of $\mathrm{HCV}$

\begin{tabular}{|c|c|c|c|}
\hline Age group & Nonreactive & Reactive (\%) & Total \\
\hline $\mathbf{7 6 5}$ yrs & 173 & $1(0.57 \%)$ & 174 \\
\hline $\mathbf{5 1 - 6 5}$ yrs & 264 & $9(3.29 \%)$ & 273 \\
\hline $\mathbf{3 6 - 5 0}$ yrs & 270 & $7(2.52 \%)$ & 277 \\
\hline $\mathbf{1 8 - 3 5}$ yrs & 317 & $6(1.85 \%)$ & 323 \\
\hline $\mathbf{1 2 - 1 7}$ yrs & 18 & $1(5.2 \%)$ & 19 \\
\hline $\mathbf{5 - 1 1}$ yrs & 11 & NIL & 11 \\
\hline $\mathbf{0 - 4}$ yrs & 3 & NIL & 3 \\
\hline Total & $\mathbf{1 0 5 6}$ & $\mathbf{2 4}(\mathbf{2 . 2 2 \%})$ & $\mathbf{1 0 8 0}$ \\
\hline
\end{tabular}

Table.4 Seroprevalence of HBV

\begin{tabular}{|c|c|c|c|}
\hline Age group & Nonreactive & Reactive (\%) & Total \\
\hline $\mathbf{> 6 5}$ yrs & 170 & $4(2.29 \%)$ & 174 \\
\hline $\mathbf{5 1 - 6 5}$ yrs & 270 & $3(1.09 \%)$ & 273 \\
\hline $\mathbf{3 6 - 5 0}$ yrs & 275 & $2(0.72 \%)$ & 277 \\
\hline $\mathbf{1 8 - 3 5}$ yrs & 311 & $5(1.58 \%)$ & 316 \\
\hline $\mathbf{1 2 - 1 7}$ yrs & 18 & NIL & 18 \\
\hline $\mathbf{5 - 1 1}$ yrs & 11 & NIL & 11 \\
\hline $\mathbf{0 - 4}$ yrs & 3 & NIL & 3 \\
\hline Total & $\mathbf{1 0 5 8}$ & $\mathbf{1 4}(\mathbf{1 . 3 \%})$ & $\mathbf{1 0 7 2}$ \\
\hline
\end{tabular}


Only one case of syphilis was reported during this period which accounted for $1.66 \%$ of prevalence rate. The seroprevalence of syphilis is comparable to another large study from a close geographical location involving more than 57,000 samples over five years with a prevalence rate of $1.27 \% .^{8}$

The observed overall seropositivity rates in our study were HIV $0.91 \%$, HCV $2.22 \%$, HBV $1.3 \%$ and syphilis $1.66 \%$. In a study from Haryana on healthy blood donors it was observed that the prevalence of $\mathrm{HIV}, \mathrm{HCV}$, HBV and syphilis was $0.3 \%, 1 \%, 1.7 \%$ and $0.9 \% .^{10}$ In another study from north India the prevalence rates in blood donors over eight year study span for HIV, HCV, HBV and syphilis were $0.24 \%, 0.43 \%, 1.18 \%$ and $0.23 \%$ with a decreasing trend over eight years. ${ }^{11}$ A study on hemodialysis patients from a closer geographical region demonstrated the prevalence of HIV, HCV and HBV as $1.02 \%$, $15.3 \%$ and $3.06 \%$ respectively. ${ }^{12}$ In our study all these ranged in between the studies on healthy blood donors and hemodialysis patients which are evidently due to a mixed patient risk profile.

The findings of our study are suggestive of a slightly higher seropositivity of HIV, HCV and HBV compared to healthy population. Its pertinent to routinely screen all the patients at baseline, especially hemodialysis patients, to avoid inadvertent exposure of healthcare staff or cross transmission to other patients admitted to the hospital.

\section{References}

Serraino R, Mazzitelli M, Greco G, Serapide F, Scaglione V, Marascio N, Trecarichi E M, Torti C. Risk factors for hepatitis $\mathrm{B}$ and $\mathrm{C}$ among healthy population: a community-based survey from four districts of Southern Italy. Infez Med. 2020 Jun 1;28(2):223-226. PMID:
32487786.

Puri P, Anand A C, Saraswat V A, Acharya S K, Sarin S K, Dhiman R K et al., Consensus Statement of HCV Task Force of the Indian National Association for Study of the Liver (INASL). Part II: INASL Recommendations for Management of $\mathrm{HCV}$ in India. J Clin Exp Hepatol. 2014 Jun;4(2):117-40. doi: 10.1016/j.jceh.2014.06.001. Epub 2014 Jun 24. PMID: 25755549; PMCID: PMC4116713.

Schweitzer A, Horn J, Mikolajczyk R T, Krause G, Ott J J. Estimations of worldwide prevalence of chronic hepatitis B virus infection: a systematic review of data published between 1965 and 2013. Lancet. 2015;386: 1546-1555.

Polaris Observatory Collaborators Global prevalence, treatment, and prevention of hepatitis B virus infection in 2016: a modelling study. Lancet Gastroenterol Hepatol. 2018;3:383-403.

National AIDS Control Organization \& ICMR-National Institute of Medical Statistics (2020). India HIV Estimates 2019: Report. New Delhi: NACO, Ministry of Health and Family Welfare, Government of India.

Bhattar S, Aggarwal P, Sahani S K, Bhalla P. Co-Infections and Sero-Prevalence of HIV, Syphilis, Hepatitis B and C Infections in Sexually Transmitted Infections Clinic Attendees of Tertiary Care Hospital in North India. J Res Health Sci. 2016 Summer;16(3):162165. PMID: 27840345; PMCID: PMC7191022.

Isac S, Ramesh B M, Rajaram S, Washington R, Bradley J E, Reza-Paul S, Beattie T $\mathrm{S}$, Alary M, Blanchard J F, Moses S. Changes in HIV and syphilis prevalence among female sex workers from three serial cross-sectional 
surveys in Karnataka state, South India. BMJ Open. 2015 Mar 27;5(3):e007106. doi: 10.1136/bmjopen-2014-007106.

PMID: 25818275; PMCID: PMC4386224.)

Patwardhan V V, Bhattar S, Bhalla P, Rawat D. Seroprevalence of syphilis by VDRL test and biological false positive reactions in different patient populations: Is it alarming? Our experience from a tertiary care center in India. Indian $\mathbf{J}$ Sex Transm Dis AIDS. 2020 Jan-Jun;41(1):43-46. doi: 10.4103/0253-7184.194317. Epub 2016 Nov 17. PMID: 33062981; PMCID: PMC7529168.

Mittal G, Gupta P, Thakuria B, Mukhiya G K, Mittal M. Profile of hepatitis B virus, hepatitis $\mathrm{C}$ virus, hepatitis $\mathrm{d}$ virus and human immunodeficiency virus infections in hemodialysis patients of a tertiary care hospital in uttarakhand. J Clin Exp Hepatol. 2013 Mar;3(1):24-8. doi: 10.1016/j.jceh.2013.02.003. Epub
2013 Feb 9. PMID: 25755468; PMCID: PMC3940102.

Arora D, Arora B, Khetarpal A. Seroprevalence of HIV, HBV, HCV and syphilis in blood donors in Southern Haryana. Indian J Pathol Microbiol. 2010 Apr-Jun;53(2):308-9. doi: 10.4103/0377-4929.64295. PMID: 20551540.

Makroo R N, Hegde V, Chowdhry M, Bhatia A, Rosamma NL. Seroprevalence of infectious markers \& their trends in blood donors in a hospital based blood bank in north India. Indian J Med Res. 2015 Sep;142(3):317-22. doi: 10.4103/0971-5916.166598. PMID: 26458348 ; PMCID: PMC4669867.

Kansay S, Sekhon J, Rana S. Seroprevalence of human immunodeficiency virus, hepatitis $\mathrm{B}$ virus, and hepatitis $\mathrm{C}$ virus among hemodialysis patients in a Tertiary Care Teaching Hospital in a developing country. Indian $\mathrm{J}$ Sex Transm Dis AIDS. 2019;40(2):120125. doi:10.4103/ijstd.IJSTD_53_17

\section{How to cite this article:}

Ashwini Manhas, Swati Mittal, Vanita Mittal, Manju Meel, Mehanaz Khan, Shashank Singh and Rathish, K. C. 2021. Seroprevalence of Viral Transfusion Transmitted Infections and Syphilis in A Tertiary Care Hospital from Haryana. Int.J.Curr.Microbiol.App.Sci. 10(08): 429434. doi: https://doi.org/10.20546/ijcmas.2021.1008.052 